\title{
Sex-related differences among ischaemic stroke patients treated with intravenous thrombolysis in Poland
}

\author{
Małgorzata Wiszniewska ${ }^{1,7}$, Waldemar Fryze ${ }^{2}$, Anna Wiśniewska², Michał Karliński ${ }^{3}$, \\ Piotr Sobolewski ${ }^{4,8}$, Grzegorz Krzykowski ${ }^{5}$, Anna Członkowska ${ }^{3,6}$ \\ ${ }^{1}$ Department of Neurology and Stroke Unit, Specialist Hospital, Pila, Poland \\ ${ }^{2}$ Department of Neurology and Stroke Unit, Copernicus Hospital, Gdansk, Poland \\ ${ }^{3}$ 2nd Department of Neurology, Institute of Psychiatry and Neurology, Warsaw, Poland \\ ${ }^{4}$ Department of Neurology and Stroke Unit, Holy Spirit Specialist Hospital, Sandomierz, Poland \\ ${ }^{5}$ Faculty of Finance and Management, WSB University in Gdansk, Gdansk, Poland \\ ${ }^{6}$ Department of Clinical and Experimental Pharmacology, Medical University of Warsaw, Warsaw, Poland \\ ${ }^{7}$ Stanisław Staszic University of Applied Sciences in Pila, Poland \\ ${ }^{8}$ Collegium Medicum, Jan Kochanowski University, Kielce, Poland
}

\begin{abstract}
Aim of study. We investigated sex differences in ischaemic stroke patients treated with intravenous alteplase. Clinical rationale for study. We suggest that it is necessary to improve care for women with atrial fibrillation. Our data suggests that closer evaluation of treatment for ischaemic stroke in men and women is needed, preferably in the form of a prospective study.

Materials and methods. This was a multicentre analysis of 1,830 ischaemic stroke patients treated with alteplase from 2004 to 2012. Data was prospectively collected in the Safe Implementation of Treatments in Stroke (SITS) registry. The main outcome measures were symptomatic intracerebral haemorrhage $(\mathrm{sICH})$ within 36 hours of treatment, three months of functional independence, and mortality.

Results. Women were significantly older (mean age 71.3 vs 66.2 years; $p<0.01$ ), more often suffered from hypertension $(78.3 \%$ vs $70.1 \% ; p<0.01$ ) and cardio-embolic strokes (34.7\% vs $27.1 \% ; p<0.01)$, and presented heavier baseline deficits. There were no differences in $\mathrm{sICH}$, but after three months fewer women were functionally independent ( $46.5 \%$ vs $53.3 \%$; $p<0.01$ ) and women had higher mortality $(26.0 \%$ vs $19.7 \%$; $p<0.01)$.

Conclusions: Of the ischaemic stroke patients treated with intravenous thrombolysis, women had worse long-term outcomes than men. This discrepancy may be explained by the older age and higher proportion of cardio-embolic strokes with more severe baseline deficits. However, multiple logistic analysis did not show that sex itself had an impact on the greater mortality in women after a stroke, or on the poorer prognosis.
\end{abstract}

Key words: alteplase, ischaemic stroke, sex differences, risk factors, outcome

(Neurol Neurochir Pol 2020; 54 (3): 272-276)

\section{Introduction}

In recent years, a lot of research has been published looking into ischaemic stroke's epidemiology, prognosis, risk factors, pathogenesis, clinical picture and course, as well as its treatment and sex-dependent outcomes [1]. Many studies have shown that women suffer from more severe strokes than men, and have less favourable prognoses, something which is additionally modified by their home country's level of development [2-9].

Women also appear to be less often treated with intravenous thrombolysis [9-13]. It is uncertain if they equally benefit from intravenous and intra-arterial thrombolysis treatment [12-17]. One should also take into account specific national or regional differences in patients' profiles [18]. 


\section{Clinical rationale for the study}

The aim of this study was to investigate sex-related differences in patient profiles and outcomes among Caucasian ischaemic stroke patients from Polish centres treated with intravenous thrombolysis.

\section{Materials and methods}

This is a retrospective multicentre analysis of 1,830 consecutive ischaemic stroke patients treated with intravenous alteplase (tPA) in Polish centres from 1 January 2004 to 31 December 2012. The data was prospectively recorded in the Safe Implementation of Treatments in Stroke - International Stroke Thrombolysis Registry [19]. The main outcome measures were: functional independence ( $0-2$ in modified Rankin Scale score-mRS) at three months; sICH within 36 hours of treatment; and three-month mortality [19]. Dependency was defined as an mRS score of 3-5 [20].

Stroke events were defined according to the World Health Organisation's criteria, and stroke was confirmed in all patients by neuroimaging [21].

Stroke subtypes were classified on admission according to the Trial of Org10172 in Acute Stroke Treatment (TOAST) criteria [22]. Stroke severity was measured using the National Institutes of Health Stroke Scale score (NIHSS) on admission and at discharge. Conventional stroke risk factors, including hypertension, diabetes mellitus, atrial fibrillation (AF), hyperlipidemia and tobacco smoking, were defined as self-reported in previous medical records or newly diagnosed. Obesity was defined as a body mass index $\geq 30 \mathrm{~kg} / \mathrm{m}^{2}$. Pre-stroke mRS, at discharge, and three months after the stroke, were assessed during an interview with the patient or his or her proxy.

\section{Statistical analysis}

Continuous variables are presented as mean with standard deviation or median and quartiles, depending on the normality of data distribution. Categorical variables are presented as a number of observations with percentage. For comparisons between men and women, Mann-Whitney U tests and Fisher's exact tests were used, as appropriate [23]. A p value $=0.05$ was considered significant. All analyses were performed in $\mathrm{R} v$. 3.4.0. [24]. A multiple logistic regression model, which was adjusted for age, onset-to-door time, door-to-treatment time, presence of hypertension, diabetes, $\mathrm{AF}$, smoking (currently), and baseline $\mathrm{mRS}$ score before stroke ( 0 and 1 only), was applied to identify factors contributed considerably to the main endpoints (death, mRS after three months, sICH according to SITS).

\section{Results}

The studied population included 1,830 consecutive ischaemic stroke patients treated with alteplase between January
2004 and December 2012 in many centres in Poland. The analysed group included 819 women (44.8\%). Women were significantly older (mean age 71.3 vs 66.2 years), were more frequently dependent before a stroke $(9.3 \%$ s $3.1 \%)$, were more often burdened with AF (35.8\% vs 26.3\%) and hypertension, but were less often smokers (13.3\% vs 33.9\%) (Tab. 1). Women suffered more severe strokes (median baseline NIHSS score $13 v s$ 11). Stroke aetiology in women was more often cardioembolic (34.7\% vs 27.1\%) (Tab. 1), although they used anticoagulants less often $(3.8 \%$ vs $4.2 \%)$.

Women had significantly longer onset-to-door time (ODT) (median 70 vs $62 \mathrm{~min}$ ) and longer onset-to-treatment time (OTT) (median 160 vs $154 \mathrm{~min}$ ), with a borderline difference in door-to-treatment time (DTT) (median 75 vs $80 \mathrm{~min}$, $\mathrm{p}=0.05$ ). Their stroke unit stay was significantly shorter (median 8.7 vs 9.1 days). There were no significant differences in the prescription rates of hypotensive medications, aspirins, vitamin K antagonists or new oral anticoagulants, but women were less likely than men to be prescribed statins on discharge from hospital ( $83.4 \%$ vs $90.1 \%)$.

Women had significantly higher mortality, both at day $7(15.5 \%$ vs $9.6 \%)$ and three months after the onset of symptoms (26.0\% vs $19.7 \%)$ (Tab. 2). This discrepancy was not modified by the presence of AF, hypertension or diabetes. There were no significant differences in the occurrence of sICH according to the ECASS (European Cooperative Acute Stroke Study) or the SITS definition (Tab. 2) [19]. However, a tendency towards a higher occurrence of sICH according to ECASS in women was particularly marked in subgroups of patients with diabetes, with heart failure, with aspirin use before stroke, and with disability before stroke (Tab. 3).

Multiple logistic analysis did not confirm that sex itself had an impact on greater mortality in women after a stroke or a worse prognosis (Tab. 4).

\section{Discussion}

In line with data from other cohorts, we found that women with acute ischaemic stroke treated with tPA are older than men and more often suffer from strokes of cardioembolic aetiology [7, 9, 17, 25-29]. However, the mean age at stroke onset among Polish women was seven years lower than in Sweden (mean age 71.3 vs 78.4 years). In other words, female Polish patients experienced a stroke seven years earlier than female Swedish patients [30]. Female Polish patients, despite a higher proportion of pre-stroke $\mathrm{AF}$, used oral anticoagulants as frequently as men $(3.8 \% v s 4.2 \%)$. Similarly to Swedish patients [30], no differences were found in the prescription rate of anticoagulants after an ischaemic stroke. Higher proportions of $\mathrm{AF}$ and hypertension in women have also been reported in other cohorts $[9,28,29,31]$.

Probably because of all the abovementioned reasons, the neurological condition on admission of women was significantly worse than men $[30,32,33]$. We observed that the ODT, 
Table 1. Sex differences in risk factors and clinical characteristics among patients with ischaemic stroke treated with intravenous thrombolysis

\begin{tabular}{|c|c|c|c|}
\hline Characteristics & Men & Women & p-value \\
\hline Cases, n (\%) & $1.011(55.2)$ & $819(44.8)$ & $<0.01$ \\
\hline Age, years, mean (SD) & $66.2(11.0)$ & $71.3(11.6)$ & $<0.01$ \\
\hline Atrial fibrillation, n (\%) & $262(26.3)$ & $289(35.8)$ & $<0.01$ \\
\hline Congestive heart failure, $\mathrm{n}(\%)$ & $214(21.5)$ & $151(18.8)$ & 0.16 \\
\hline Hyperlipidemia, n (\%) & $317(33.4)$ & $254(32.6)$ & 0.76 \\
\hline Hypertension, n (\%) & $700(70.1)$ & $637(78.3)$ & $<0.01$ \\
\hline Diabetes mellitus, $\mathrm{n}(\%)$ & $184(18.4)$ & $171(21.1)$ & 0.15 \\
\hline Previous stroke, n (\%) & $138(13.8)$ & $107(13.2)$ & 0.78 \\
\hline Smoking - previous, n (\%) & $189(28)$ & $47(6.8)$ & $<0.01$ \\
\hline Smoking - current, n (\%) & $324(33.9)$ & $106(13.3)$ & $<0.01$ \\
\hline Baseline NIHSS score, median (Q1-Q3) & $11(7-16)$ & $13(7.5-18)$ & $<0.01$ \\
\hline SBP mean, mm Hg (SD) & $151.4(20.8)$ & $152.4(20.4)$ & 0.18 \\
\hline DBP mean, mm Hg (SD) & $85.7(13.1)$ & $83.7(12.9)$ & $<0.01$ \\
\hline Glucose, mg/dl, (SD) & $131.1(47.3)$ & $135.5(49.3)$ & 0.01 \\
\hline Large-vessel disease, CAS, n (\%) & $155(16.6)$ & $69(9.3)$ & $<0.01$ \\
\hline Large vessel disease, other, $\mathrm{n}(\%)$ & $301(32.2)$ & $249(33.4)$ & 0.64 \\
\hline Cardio-embolic, n (\%) & $253(27.1)$ & $259(34.7)$ & $<0.01$ \\
\hline Lacunar stroke, n (\%) & $57(6.1)$ & $57(7.6)$ & 0.24 \\
\hline Other/unusual n (\%) & $35(6.0)$ & $56(4.7)$ & 0.28 \\
\hline Unknown, n (\%) & $111(11.9)$ & $76(10.2)$ & 0.31 \\
\hline
\end{tabular}

SBP - systolic blood pressure; DBP — diastolic blood pressure

Table 2. Sex differences in outcomes at three months after ischaemic stroke treated with alteplase

\begin{tabular}{|c|c|c|c|}
\hline Outcome & Men & Women & p-value \\
\hline Death, n (\%) & $199(19.7)$ & $213(26.0)$ & $<0.01$ \\
\hline mRS 0-1, n (\%) & $358(35.4)$ & $245(29.9)$ & $<0.01$ \\
\hline mRS 0-2, n (\%) & $539(53.3)$ & 381 (46.5) & $<0.01$ \\
\hline Intracerebral haemorrhage according to ECASS def., n (\%) & $45(4.7)$ & $50(6.5)$ & 0.11 \\
\hline Intracerebral haemorrhage according to SITS def., n (\%) & $14(1.5)$ & $16(2.0)$ & 0.36 \\
\hline
\end{tabular}

ECASS - European Cooperative Acute Stroke Study; SITS — Safe Implementation of Treatments in Stroke; mRS — modified Rankin Scale score

Table 3. Frequency of symptomatic intracerebral haemorrhage $(\mathrm{sICH})$ according to ECASS definition in women and men depending on presence of additional factor

\begin{tabular}{|c|c|c|c|c|c|}
\hline \multirow[t]{2}{*}{ Additional factor } & \multicolumn{2}{|c|}{$\begin{array}{l}\text { Men } \\
\text { sICH }\end{array}$} & \multicolumn{2}{|c|}{$\begin{array}{l}\text { Women } \\
\text { sICH }\end{array}$} & \multirow[t]{2}{*}{ p-value } \\
\hline & with factor & without factor & with factor & without factor & \\
\hline Diabetes, n (\%) & $9(5.3)$ & $36(4.6)$ & $13(8.0)$ & $36(6.0)$ & $1.36(\mathrm{Cl} 0.52-3.08)$ \\
\hline Atrial fibrillation, n (\%) & $20(8.2)$ & $23(3.3)$ & $27(9.9)$ & $22(4.5)$ & $1.31(\mathrm{Cl} 0.74-2.56)$ \\
\hline Hypertension, n (\%) & $8(4.8)$ & $12(4.2)$ & $42(7.0)$ & $32(4.8)$ & $1.4(\mathrm{Cl} 0.86-2.27)$ \\
\hline Heart failure, n (\%) & $11(5.5)$ & $32(4.3)$ & $15(10.9)$ & $34(5.5)$ & $1.47(\mathrm{Cl} 0.66-3.38)$ \\
\hline Aspirin use before stroke, $n(\%)$ & $12(4.0)$ & $28(4.4)$ & $21(8.4)$ & $28(5.6)$ & $1.56(\mathrm{Cl} 0.75-3.28)$ \\
\hline $\begin{array}{l}\text { Disability before stroke, (mRS > } \\
\text { 1) } n(\%)\end{array}$ & $3(4.5)$ & $39(4.5)$ & $14(11.3)$ & $32(5.1)$ & $1.28(\mathrm{Cl} 0.78-2.05)$ \\
\hline
\end{tabular}


Table 4. Multiple regression logistic model adjusted for age, onset-to-door time (OTD), door-to-treatment time (DTT), presence of hypertension, diabetes mellitus, AF, smoking (current), score $0-1$ in mRS before stroke, initial stroke severity on NIHSS scale

$\begin{array}{lccc}\text { Variable } & \text { OR } \pm \mathbf{9 7 . 5} \mathbf{C l} & \mathbf{2 . 5 \%} \mathbf{C l} & \mathbf{9 7 . 5 \%} \mathbf{C l} \\ \text { Death } & 1.2104 & 0.8752 & 1.6736 \\ \text { Intracerebral haemorrhage according to SITS def. } & 1.2493 & 0.5059 & 3.12222 \\ \text { mRS 0-1 after 3 months } & 1.0037 & 0.7803 & 1.2909 \\ \text { mRS 0-2 after 3 months } & 1.0137 & 0.7851 & 1.3098\end{array}$

$\mathrm{OR}$ - odds ratio; $\mathrm{Cl}-95 \%$ confidence interval; SITS - Safe Implementation of Treatments in Stroke; $\mathrm{mRS}$ - modified Rankin Scale score

as well as the OTT, in women was on average several minutes longer than in men. This might be caused by their older age, more frequent functional dependence, and more frequent living alone [32]. The difference may not be of major clinical importance overall, but it still deserves to be addressed. Attempts should be made to equip older women who live alone with the knowledge of how to recognise stroke and how to react. It might also be profitable to consider providing them with a special device to facilitate communication with ambulances in case of emergency. As there were no differences in DTT, we can assume that the processing of patients qualified for tPA is equal for both sexes while in hospital.

Yeo et al. [15] observed, in a group of 2,460 ischaemic stroke patients treated with intravenous alteplase, that if the outcome of women improved significantly (a 10 or more points reduction in NIHSS scale) within 2-24 hours, there was a doubled chance of regaining full independence at three months after an ischaemic stroke. This illustrates the necessity of women receiving particularly good care within the first 24 hours from the onset of an ischaemic stroke. If such care were to become standard, then the number of women with greater independence at three months would increase.

Our study has some limitations. It used data from a voluntary multicentre registry. The evaluation of control CT scan was performed on site, and the diagnosis of sICH was made at the discretion of an attending physician. It is impossible to determine how many patients were not reported, and why. Because only a fraction of Polish stroke centres participate in the SITS, one may expect that our results are generalisable to dedicated stroke units, but probably not fully to all Polish stroke units. Nonetheless, the registry provides the best available multicentre real life data.

\section{Clinical implications/future directions}

Our findings confirm that there are several important sex-related differences in ischaemic stroke patients treated with intravenous alteplase. Although women do not seem to be at a clearly increased risk of intracerebral haemorrhage, they more often have a poor long-term outcome and higher mortality. This discrepancy may be to some extent explained by the older age and higher proportion of cardio-embolic strokes with more severe baseline deficit.
One may assume that the optimisation of primary prevention, improved stroke awareness, and improved communication with ambulance dispatchers could reduce the gap between men and women. Therefore, specific central health policies should be encouraged and properly implemented.

Our data suggests that closer evaluation of the treatment of ischaemic stroke in men and women in Poland is needed, preferably in the form of a prospective study. It is also necessary to improve care for women with $\mathrm{AF}$.

\section{Conflict of interests: None}

\section{References}

1. Reeves MJ, Bushnell CD, Howard G, et al. Sex differences in stroke: epidemiology, clinical presentation, medical care, and outcomes. Lancet Neurol. 2008; 7(10): 915-926, doi: 10.1016/S14744422(08)70193-5, indexed in Pubmed: 18722812.

2. Bousser MG. Stroke in women: the 1997 Paul Dudley White International Lecture. Circulation. 1999; 99(4): 463-467, doi: 10.1161/01. cir.99.4.463, indexed in Pubmed: 9927389.

3. Di Carlo A, Lamassa M, Baldereschi M, et al. European BIOMED Study of Stroke Care Group. Sex differences in the clinical presentation, resource use, and 3-month outcome of acute stroke in Europe: data from a multicenter multinational hospital-based registry. Stroke. 2003; 34(5): 1114-1119, doi: 10.1161/01.STR.0000068410.07397. D7, indexed in Pubmed: 12690218.

4. Roquer J, Campello AR, Gomis M. Sex differences in first-ever acute stroke. Stroke. 2003; 34(7): 1581-1585, doi: 10.1161/01. STR.0000078562.82918.F6, indexed in Pubmed: 12805490.

5. Kapral MK, Fang J, Hill MD, et al. Investigators of the Registry of the Canadian Stroke Network. Sex differences in stroke care and outcomes: results from the Registry of the Canadian Stroke Network. Stroke. 2005; 36(4): 809-814, doi: 10.1161/01.STR.0000157662.09551. e5, indexed in Pubmed: 15731476.

6. Kim JS, Lee KB, Roh H, et al. Gender differences in the functional recovery after acute stroke. J Clin Neurol. 2010; 6(4): 183-188, doi: 10.3988/jcn.2010.6.4.183, indexed in Pubmed: 21264198.

7. Turaj W, Slowik A, Wnuk M, et al. Gender-related differences in diagnostic evaluation and outcome of ischemic stroke in Poland. Stroke. 2009; 40(3): 980-982, doi: 10.1161/STROKEAHA.108.528422, indexed in Pubmed: 19164792.

8. Knauft W, Chhabra J, McCullough LD. Emergency department arrival times, treatment, and functional recovery in women with acute ischemic stroke. J Womens Health (Larchmt). 2010; 19(4): 681-688, doi: 10.1089/jwh.2009.1616, indexed in Pubmed: 20187750. 
9. Barker-Collo S, Bennett DA, Krishnamurthi RV, et al. GBD 2013 Writing Group, GBD 2013 Stroke Panel Experts Group. Sex Differences in Stroke Incidence, Prevalence, Mortality and Disability-Adjusted Life Years: Results from the Global Burden of Disease Study 2013. Neuroepidemiology. 2015; 45(3): 203-214, doi: 10.1159/000441103, indexed in Pubmed: 26505984.

10. Gainey J, Brechtel L, Konklin S, et al. In a stroke cohort with incident hypertension; are more women than men likely to be excluded from recombinant tissue-type Plasminogen Activator (rtPA)? J Neurol Sci. 2018; 387: 139-146, doi: 10.1016/j.jns.2018.02.016, indexed in Pubmed: 29571851.

11. Buijs JE, Uyttenboogaart M, Brouns R, et al. The Effect of Age and Sex on Clinical Outcome after Intravenous Recombinant Tissue Plasminogen Activator Treatment in Patients with Acute Ischemic Stroke. J Stroke Cerebrovasc Dis. 2016; 25(2): 312-316, doi: 10.1016/j. jstrokecerebrovasdis.2015.09.035, indexed in Pubmed: 26527412.

12. Wapshott T, Blum B, Kelsey W, et al. Investigation of Gender Differences and Exclusive Criteria in a Diabetic Acute Ischemic Stroke Population Treated with Recombinant Tissue-Type Plasminogen Activator (rtPA). J Vasc Interv Neurol. 2017; 9(6): 26-32, indexed in Pubmed: 29445435.

13. Boehme AK, Siegler JE, Mullen MT, et al. Racial and gender differences in stroke severity, outcomes, and treatment in patients with acute ischemic stroke. J Stroke Cerebrovasc Dis. 2014; 23(4): e255e261, doi: 10.1016/j.jstrokecerebrovasdis.2013.11.003, indexed in Pubmed: 24468069.

14. Lorenzano S, Ahmed N, Falcou A, et al. SITS Investigators. Does sex influence the response to intravenous thrombolysis in ischemic stroke?: answers from safe implementation of treatments in Stroke-International Stroke Thrombolysis Register. Stroke. 2013; 44(12): 3401-3406, doi: 10.1161/STROKEAHA.113.002908, indexed in Pubmed: 24172579.

15. Yeo LLL, Paliwal P, Teoh HL, et al. Early and continuous neurologic improvements after intravenous thrombolysis are strong predictors of favorable long-term outcomes in acute ischemic stroke. J Stroke Cerebrovasc Dis. 2013; 22(8): e590-e596, doi: 10.1016/j.jstrokecerebrovasdis.2013.07.024, indexed in Pubmed: 23954601.

16. Elkind MSV, Prabhakaran S, Pittman J, et al. GAIN Americas Investigators. Sex as a predictor of outcomes in patients treated with thrombolysis for acute stroke. Neurology. 2007; 68(11): 842-848, doi: 10.1212/01. wnl.0000256748.28281.ad, indexed in Pubmed: 17353472.

17. Willers C, Lekander I, Ekstrand E, et al. Sex as predictor for achieved health outcomes and received care in ischemic stroke and intracerebral hemorrhage: a register-based study. Biol Sex Differ. 2018; 9(1): 11, doi: 10.1186/s13293-018-0170-1, indexed in Pubmed: 29514685.

18. Martínez-Sánchez P, Fuentes B, Fernández-Domínguez J, et al. Young women have poorer outcomes than men after stroke. Cerebrovasc Dis. 2011; 31(5): 455-463, doi: 10.1159/000323851, indexed in Pubmed: 21346351.

19. Seet RCS, Rabinstein AA. Symptomatic intracranial hemorrhage following intravenous thrombolysis for acute ischemic stroke: a critical review of case definitions. Cerebrovasc Dis. 2012; 34(2): 106-114, doi: 10.1159/000339675, indexed in Pubmed: 22868870.
20. Banks JL, Marotta CA. Outcomes validity and reliability of the modified Rankin scale: implications for stroke clinical trials: a literature review and synthesis. Stroke. 2007; 38(3): 1091-1096, doi: 10.1161/01. STR.0000258355.23810.c6, indexed in Pubmed: 17272767.

21. Stroke-1989. Recommendations on stroke prevention, diagnosis, and therapy. Report of the WHO Task Force on Stroke and other Cerebrovascular Disorders. Stroke. 1989; 20(10): 1407-1431, doi: 10.1161/01.str.20.10.1407, indexed in Pubmed: 2799873.

22. Adams HP, Bendixen BH, Kappelle $\sqcup$, et al. Classification of subtype of acute ischemic stroke. Definitions for use in a multicenter clinical trial. TOAST. Trial of Org 10172 in Acute Stroke Treatment. Stroke. 1993; 24(1): 35-41, doi: 10.1161/01.str.24.1.35.

23. Altman DG. Practical Statistics for medical Research, 2nd. ed. Chapman \& Hall/CRC, Boca Raton, Florida. ; 2001.

24. R Development Core Team R: A Language and Environment for Statistical Computing. R Foundation for Statistical Computing, Vienna, Austria 2007. ISBN 3-900051-07-0, http://www.R-project.org.

25. Touzé $E$, Rothwell PM. Sex differences in heritability of ischemic stroke: a systematic review and meta-analysis. Stroke. 2008; 39(1): 16-23, doi: 10.1161/STROKEAHA.107.484618, indexed in Pubmed: 18032738.

26. Wang L, Yanuck D, Beecham A, et al. A candidate gene study revealed sex-specific association between the OLR1 gene and carotid plaque. Stroke. 2011; 42(3): 588-592, doi: 10.1161/STROKEAHA.110.596841, indexed in Pubmed: 21257822.

27. Yu C, An Z, Zhao W, et al. Sex Differences in Stroke Subtypes, Severity, Risk Factors, and Outcomes among Elderly Patients with Acute Ischemic Stroke. Front Aging Neurosci. 2015; 7: 174, doi: 10.3389/ fnagi.2015.00174, indexed in Pubmed: 26441636.

28. Starostka-Tatar A, Łabuz-Roszak B, Skrzypek M, et al. Characteristics of hospitalizations due to acute stroke in the Silesian Province, Poland, between 2009 and 2015. Neurol Neurochir Pol. 2018; 52(2): 252-262, doi: 10.1016/j.pjnns.2017.11.010, indexed in Pubmed: 29221869.

29. Wiśniewski A, Sikora J, Filipska K, et al. Assessment of the relationship between platelet reactivity, vascular risk factors and gender in cerebral ischaemia patients. Neurol Neurochir Pol. 2019; 53(4): 258-264, doi: 10.5603/PJNNS.a2019.0028, indexed in Pubmed: 31343071.

30. Eriksson M, Glader EL, Norrving Bo, et al. Sex differences in stroke care and outcome in the Swedish national quality register for stroke care. Stroke. 2009; 40(3): 909-914, doi: 10.1161/STROKEAHA.108.517581, indexed in Pubmed: 19118246.

31. Zou C, Wei C, Wang Z, et al. Sex differences in outcomes and risk factors among elderly patients with ischemic stroke. Oncotarget. 2017; 8(61): 104582-104593, doi: 10.18632/oncotarget.21967, indexed in Pubmed: 29262663.

32. Messé SR, Khatri P, Reeves MJ, et al. Why are acute ischemic stroke patients not receiving IV tPA? Results from a national registry. Neurology. 2016; 87(15): 1565-1574, doi: 10.1212/WNL.0000000000003198, indexed in Pubmed: 27629092.

33. Förster A, Gass A, Kern R, et al. Gender differences in acute ischemic stroke: etiology, stroke patterns and response to thrombolysis. Stroke. 2009; 40(7): 2428-2432, doi: 10.1161/STROKEAHA.109.548750, indexed in Pubmed: 19461021. 